\title{
Correction to: Prospective associations between recalled parental bonding and perinatal depression: a cohort study in urban and rural Turkey
}

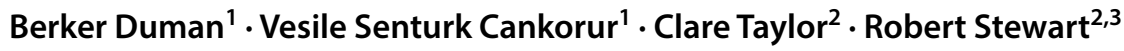

Published online: 25 April 2018

(c) The Author(s) 2018

\section{Correction to: \\ Social Psychiatry and Psychiatric Epidemiology (2018) 53:385-392 \\ https://doi.org/10.1007/s00127-018-1484-3}

The article 'Prospective associations between recalled parental bonding and perinatal depression: a cohort study in urban and rural Turkey, written by Berker Duman, Vesile Senturk Cankorur, Clare Taylor and Robert Stewart was originally published electronically on the publisher's internet portal (currently SpringerLink) on January 10, 2018 without open access.

With the author(s)' decision to opt for Open Choice the copyright of the article changed on April 23, 2018 to (C) The Author(s) 2018 and the article is forthwith distributed under the terms of the Creative Commons Attribution 4.0
International License (http://creativecommons.org/licenses/ by/4.0/), which permits use, duplication, adaptation, distribution and reproduction in any medium or format, as long as you give appropriate credit to the original author(s) and the source, provide a link to the Creative Commons license and indicate if changes were made.
Berker Duman

berker.duman@kcl.ac.uk

Vesile Senturk Cankorur vesile.senturk@kcl.ac.uk

Clare Taylor

clare.1.taylor@kcl.ac.uk

Robert Stewart

robert.stewart@kcl.ac.uk

1 Department of Psychiatry, Ankara University Faculty of Medicine, Dikimevi, 06100 Ankara, Turkey

2 King's College London (Institute of Psychiatry, Psychology and Neuroscience), London, UK

3 South London and Maudsley NHS Foundation Trust, London, UK 